\title{
Evaluation Technique of Chloride Penetration Using Apparent Diffusion Coefficient and Neural Network Algorithm
}

\author{
Yun-Yong Kim, ${ }^{1}$ Byung-Jae Lee, ${ }^{2}$ and Seung-Jun Kwon ${ }^{3}$ \\ ${ }^{1}$ Civil Engineering, Chungnam National University, 99 Daehak-ro, Yuseong-gu, Daejeon 305-764, Republic of Korea \\ ${ }^{2}$ ReD Center, JNTINC Co., Ltd., No. 9, Hyundaikia-ro 830beon-Gil, Bibong-myeon, Hwaseong, \\ Gyeonggi-do 445-842, Republic of Korea \\ ${ }^{3}$ Civil and Environmental Engineering, Hannam University, 133 Ojeong-dong, Daedeok-gu, Daejeon 306-791, Republic of Korea
}

Correspondence should be addressed to Seung-Jun Kwon; jjuni98@hannam.ac.kr

Received 3 June 2014; Accepted 11 August 2014; Published 11 September 2014

Academic Editor: Tao Zhang

Copyright (C) 2014 Yun-Yong Kim et al. This is an open access article distributed under the Creative Commons Attribution License, which permits unrestricted use, distribution, and reproduction in any medium, provided the original work is properly cited.

Diffusion coefficient from chloride migration test is currently used; however this cannot provide a conventional solution like total chloride contents since it depicts only ion migration velocity in electrical field. This paper proposes a simple analysis technique for chloride behavior using apparent diffusion coefficient from neural network algorithm with time-dependent diffusion phenomena. For this work, thirty mix proportions of high performance concrete are prepared and their diffusion coefficients are obtained after long term- $\mathrm{NaCl}$ submerged test. Considering time-dependent diffusion coefficient based on Fick's 2nd Law and NNA (neural network algorithm), analysis technique for chloride penetration is proposed. The applicability of the proposed technique is verified through the results from accelerated test, long term submerged test, and field investigation results.

\section{Introduction}

Chloride ions induced into concrete cause a severe corrosion in embedded steel and the durability degradation propagates to structural safety problem [1]. In the earlier researches on deterioration of chloride attack, studies based on field investigations and apparent diffusion have been performed [2-4]. Recently, micromodels based on mass conservation law and behaviors in early aged concrete like porosity, hydration, and saturation have been proposed [5-7]. Furthermore various phenomena like enlarged diffusion and permeation due to cracks and cold joint are considered for quantitative modeling on chloride penetration $[8,9]$.

Apparent diffusion coefficient based on Fick's 2nd law is conventionally utilized for evaluating chloride behavior, however migration test and the related techniques are frequently utilized for measuring a resistance to chloride penetration $[10,11]$ since apparent diffusion coefficient experimentally obtained needs considerably long period. Chloride diffusion coefficients from migration tests indicate ion velocity in electrical field so that they cannot be directly employed to Fick' 2nd law. For evaluation of chloride behavior using diffusion coefficient from migration test, complicated analysis frame is required $[12,13]$. For evaluation of total chloride content, special relationship between free and bound chloride ion, so called isotherm, should be considered in the analysis frame $[6,14,15]$. Apparent diffusion coefficient can provide direct solution-chloride content based on Fick's 2nd Law to engineers, and this technique has been widely applied for its simple formulation and several familiar-powerful programs like Life 365 [3, 16]. Additionally several engineering advantages like easy employing time effect on diffusion behavior [16] and random variables for stochastic approach [8] are found through treating apparent diffusion coefficient.

NNA (neural network algorithm) is one of the optimization techniques and this has been widely utilized for determination of mix proportions and strength evaluation in concrete research field [17-20]. For analysis of chloride behavior and carbonation, NNA technique is recently adopted [21, 22] but the related analysis technique needs such complicated micromodels and major assumptions that it is not widely used for engineers. 
TABLE 1: Chemical and physical properties of cement and mineral admixtures.

\begin{tabular}{|c|c|c|c|c|c|c|c|c|c|}
\hline \multirow{3}{*}{ Types } & \multicolumn{9}{|c|}{ Items } \\
\hline & \multicolumn{7}{|c|}{ Chemical composition (\%) } & \multicolumn{2}{|c|}{ Physical properties } \\
\hline & $\mathrm{SiO}_{2}$ & $\mathrm{Al}_{2} \mathrm{O}_{3}$ & $\mathrm{Fe}_{2} \mathrm{O}_{3}$ & $\mathrm{CaO}$ & $\mathrm{MgO}$ & $\mathrm{SO}_{3}$ & Ig. loss & Specific gravity $\left(\mathrm{g} / \mathrm{cm}^{3}\right)$ & Blaine $\left(\mathrm{cm}^{2} / \mathrm{g}\right)$ \\
\hline $\mathrm{OPC}$ & 21.96 & 5.27 & 3.44 & 63.41 & 2.13 & 1.96 & 0.79 & 3.16 & 3,214 \\
\hline GGBFS & 32.74 & 13.23 & 0.41 & 44.14 & 5.62 & 1.84 & 0.2 & 2.89 & 4,340 \\
\hline FA & 55.66 & 27.76 & 7.04 & 2.70 & 1.14 & 0.49 & 4.3 & 2.19 & 3,621 \\
\hline SF & 93.3 & 0.5 & 1.21 & 0.27 & 1.03 & 0.02 & 1.1 & 2.21 & 190,620 \\
\hline
\end{tabular}

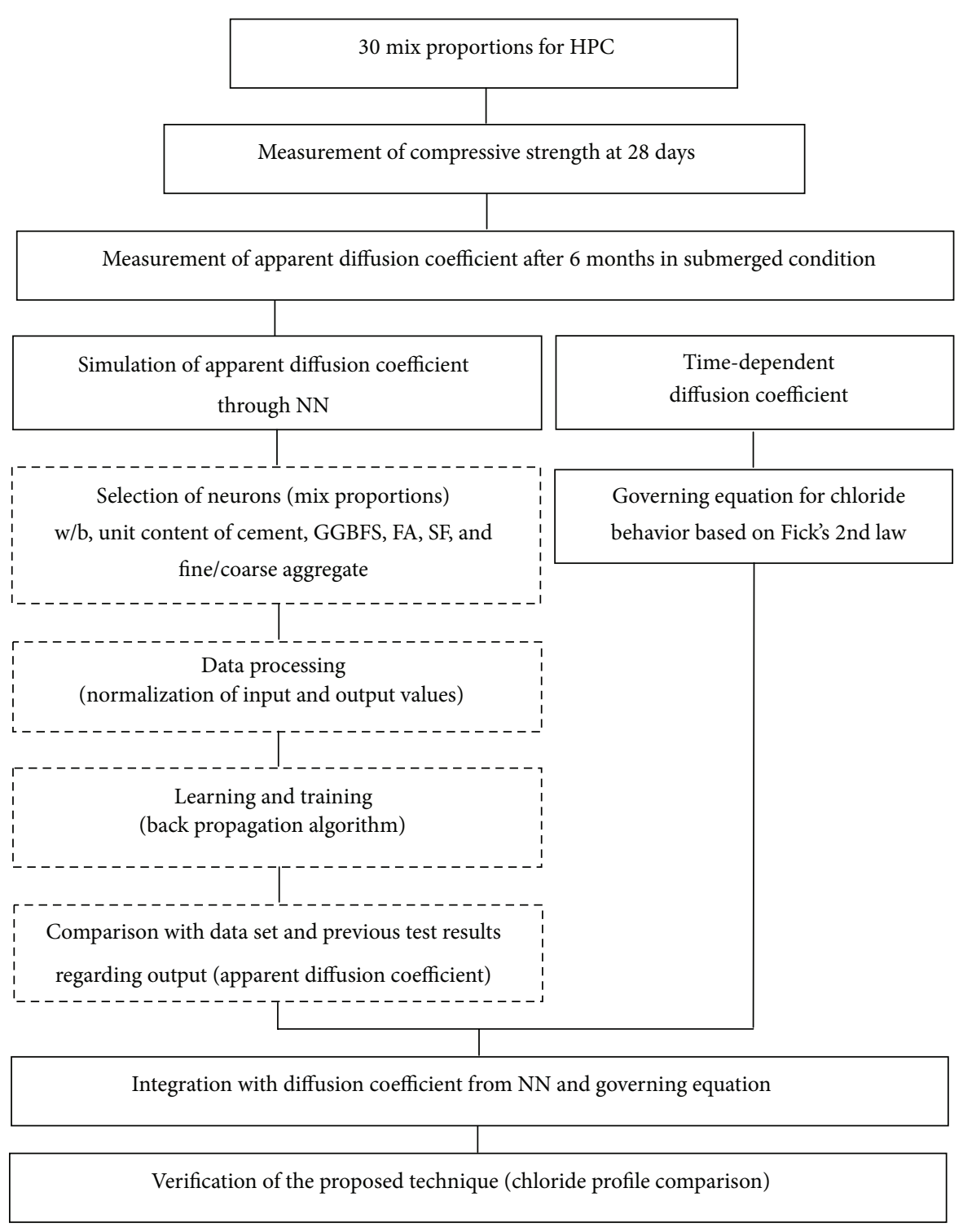

FIGURE 1: Flowchart for this study.

In this paper, apparent diffusion coefficients, which can provide a direct solution (chloride content), are obtained from chloride-submerged condition for 6 months. Major mix components are selected as neurons and training for learning is carried out for optimum apparent diffusion coefficients. The simulated diffusion coefficients are verified with test results. A simple and deterministic analysis technique for chloride behavior is proposed considering time-dependent diffusion characteristics and the apparent diffusion coefficient from NNA. In this paper, diffusion 


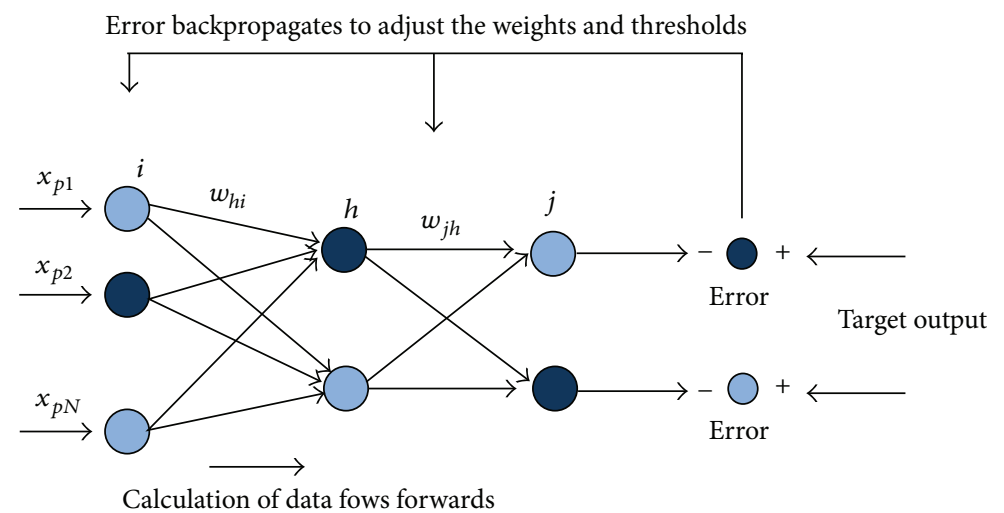

(a) Simple neural network architecture
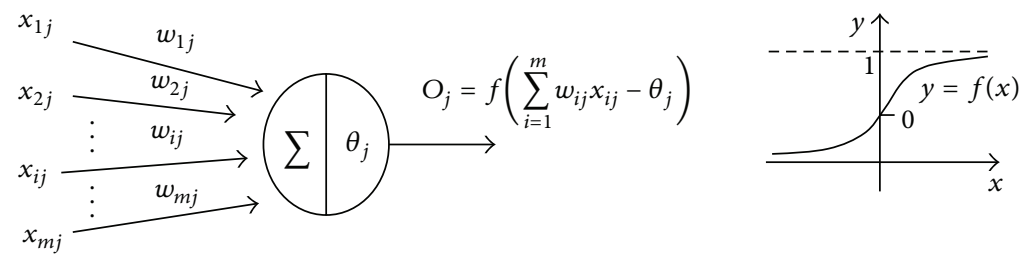

(b) Activation function

FIGURE 2: Schematic diagram for simple NNA architecture [22, 24].

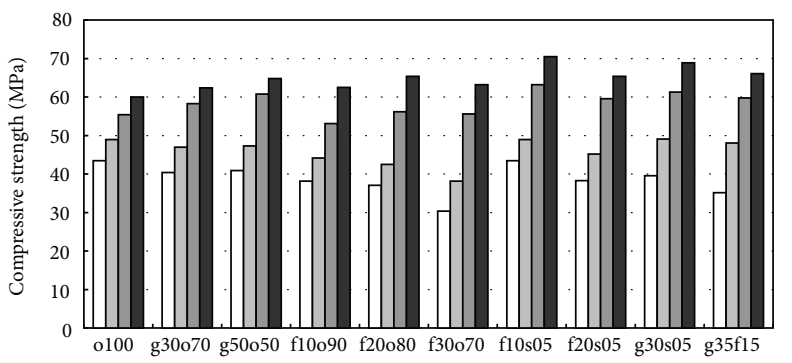

(a) $w / b 0.37$ series

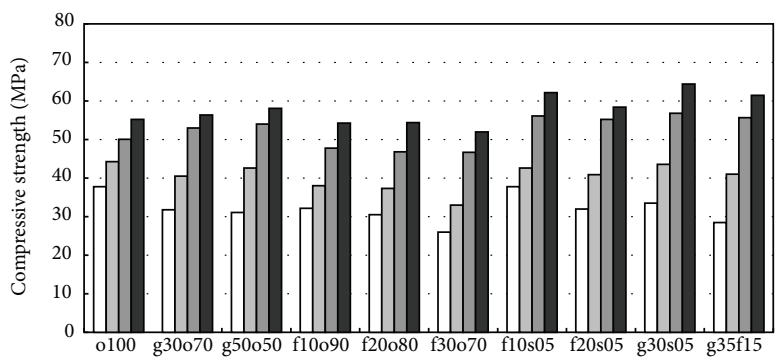

(b) w/b 0.42 series

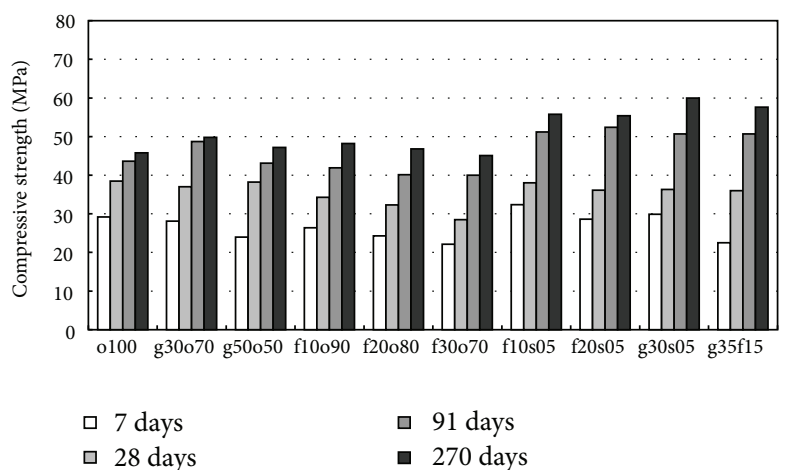

(c) $w / b 0.47$ series

FIGURE 3: Strength development with admixtures and curing periods.

coefficients from various HPC (high performance concrete) mix proportions, NNA application for reasonable selection of diffusion coefficients, and simple technique for chloride penetration prediction are dealt with. In Figure 1, flow chart for the work is shown.

\section{Outline of NNA}

It is reported that NNA was started by McCulloch and Pitt [23]. A neuron as a unit with process of stimulus and reaction is modeled in the system. The training for learning a data set 


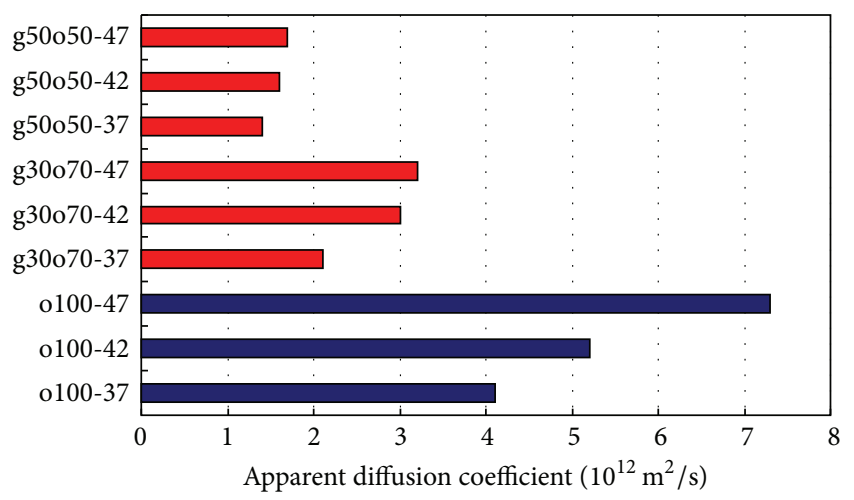

(a) OPC and slag mixture series with various $\mathrm{w} / \mathrm{b}$ ratios

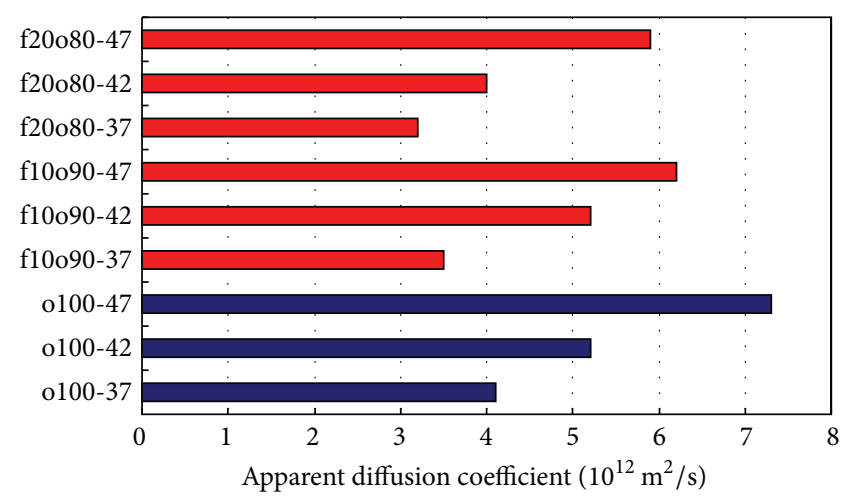

(b) OPC and fly ash series with various $w / b$ ratios

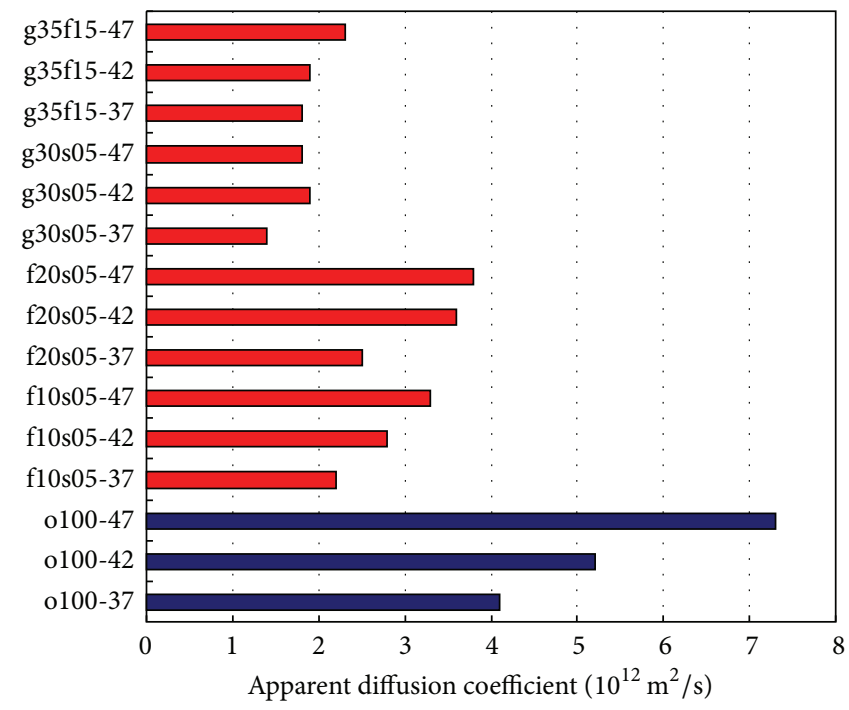

(c) OPC and combined mixture series with various w/b ratios

FIGURE 4: Comparison of measured diffusion coefficient with OPC concrete.

TABLE 2: Physical properties of aggregates.

\begin{tabular}{lcccc}
\hline Types & \multicolumn{5}{c}{$\begin{array}{c}\text { Items } \\
G_{\max } \\
(\mathrm{mm})\end{array}$} & $\begin{array}{c}\text { Specific gravity } \\
\left(\mathrm{g} / \mathrm{cm}^{3}\right)\end{array}$ & $\begin{array}{c}\text { Absorption } \\
(\%)\end{array}$ & F.M. \\
\hline Fine aggregate & - & 2.58 & 1.01 & 2.90 \\
Coarse aggregate & 25 & 2.64 & 0.82 & 6.87 \\
\hline
\end{tabular}

is conducted with connection strength, transfer function, and biases. The errors between calculated and expected results are reduced with increasing epochs. The training for learning is completed when the error decreases to a target convergence level. In this paper, a back-propagation algorithm is adopted for the neural network. Figure 2 shows an outline of simple neural network architecture [22, 24].

In this network, each element of input is connected to each neuron input through the weight matrix. Neurons $\left(N_{j}\right)$ and activated values $\left(H_{j}\right)$ in the hidden layer are formulated as (1) and (2). Activated value, $O_{k}$ can be written as (3). Consider

$$
\begin{gathered}
N_{j}=\sum W_{j i} I_{i}, \\
H_{j}=f\left(N_{j}+B_{j}\right), \\
O_{k}=f\left(\sum W_{k j} H_{j}+B_{k}\right),
\end{gathered}
$$

where $I_{j}$ is input vector, $W_{j i}$ is weight or connection strength, $f$ is transfer function, and $B_{j}$ is bias. In the back-propagation, error $(E)$ is calculated through (4) considering target value $\left(T_{k}\right)$. Consider

$$
E=\frac{1}{2}\left(\sum_{k=1} O_{k}-T_{k}\right)^{2}
$$


TABLE 3: Mix proportions for HPC.

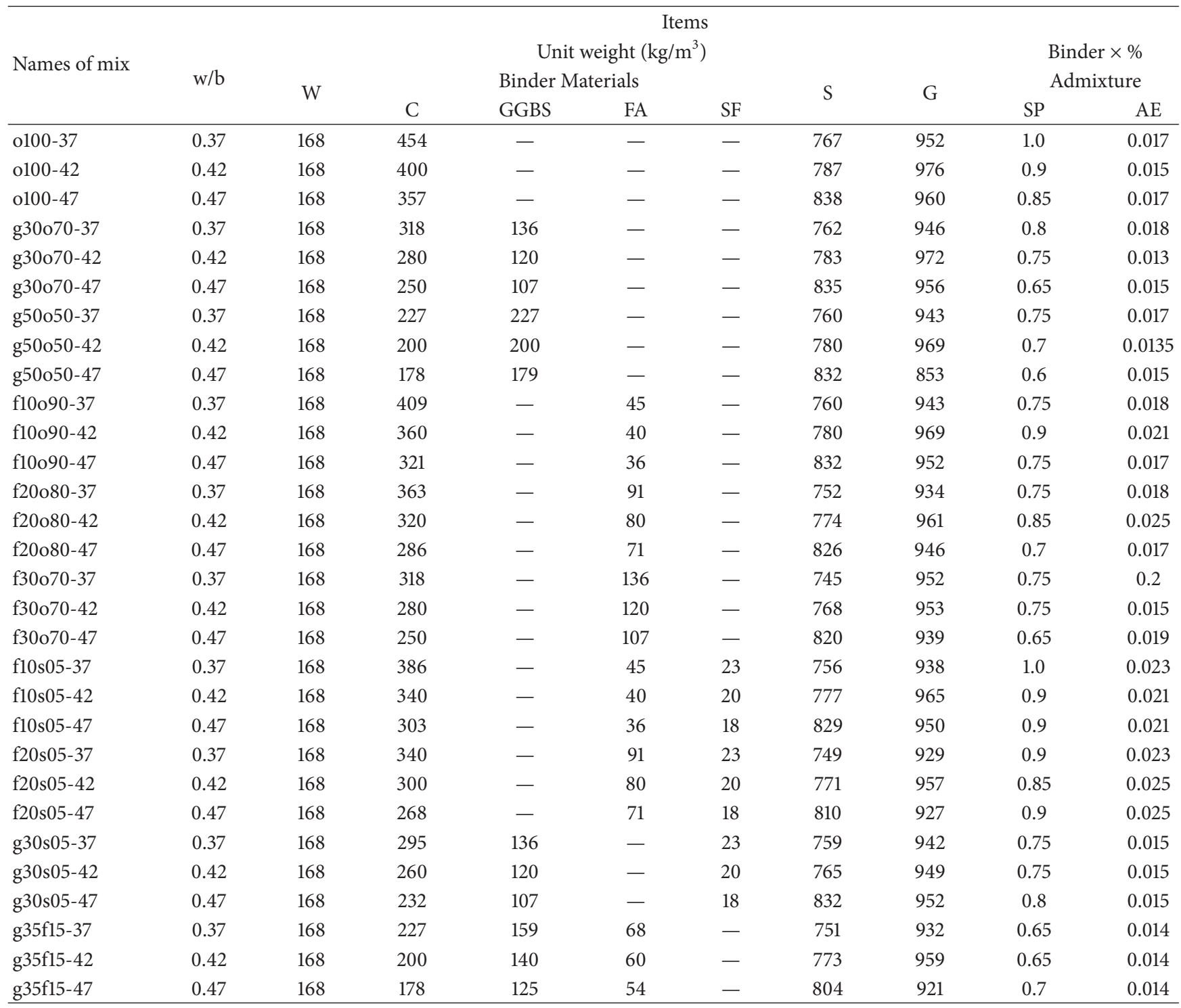

w/b: water to binder ratio.

G: gravel.

AE: air entrainer.

S: sand.

SP: superplasticizer.

For minimizing the error, connection strength $\left(W_{i j}\right)$ is modified backward form neurons in output layer like

$$
\begin{array}{ccc}
\Delta W_{k j}=\eta \delta_{k} H_{j}, & \Delta B_{k}=\eta \delta_{k}, & \delta_{k}=\left(T_{k}-O_{k}\right) f^{\prime}\left(N_{k}\right), \\
\Delta W_{j i}=\eta \delta_{j} H_{i}, & \Delta B_{j}=\eta \delta_{j}, & \delta_{j}=\left(W_{k j} \delta_{k}\right) f^{\prime}\left(N_{j}\right),
\end{array}
$$

where $\delta_{j}$ and $\delta_{k}$ are gradients of the total error, and $\eta$ is the learning rate.

After the modification of connection strength, NNA repeats the process of calculation and modification until the error decreases within the target convergence.
For the data set, each input should have boundary limits from 0.0 to 1.0. Through data process like (6), each value satisfies the boundary limit. Consider

$$
P_{n}=\frac{P_{\mathrm{act}}-P_{\min }}{P_{\max }-P_{\min }},
$$

where $P_{n}$ is input value for training, $P_{\text {act }}$ is actual input data, and $P_{\max }$ and $P_{\min }$ are maximum and minimum values of input data. After calculation, the output value with a range of $0.0 \sim 1.0$ is obtained and it should be converted to actual value using (6). 
TABLE 4: Results of apparent diffusion coefficient.

\begin{tabular}{|c|c|}
\hline Mixture & Diffusion coefficient $\left(\mathrm{m}^{2} / \mathrm{sec}\right)$ \\
\hline o100-37 & $4.1 E-12$ \\
\hline o100-42 & $5.2 E-12$ \\
\hline o100-47 & $7.3 E-12$ \\
\hline g30o70-37 & $2.1 E-12$ \\
\hline g30o70-42 & $3.0 E-12$ \\
\hline g30o70-47 & $3.2 E-12$ \\
\hline g50o50-37 & $1.4 E-12$ \\
\hline g50o50-42 & $1.6 E-12$ \\
\hline g50o50-47 & $1.7 E-12$ \\
\hline f10o90-37 & $3.5 E-12$ \\
\hline f10o90-42 & $5.2 E-12$ \\
\hline f10o90-47 & $6.2 E-12$ \\
\hline $\mathrm{f} 20 \mathrm{o} 80-37$ & $3.2 E-12$ \\
\hline $\mathrm{f} 20 \mathrm{o} 80-42$ & $4.0 E-12$ \\
\hline $\mathrm{f} 20 \mathrm{o} 80-47$ & $5.9 E-12$ \\
\hline f30o70-37 & $3.9 E-12$ \\
\hline $\mathrm{f} 30 \mathrm{o} 70-42$ & $4.3 E-12$ \\
\hline f30o70-47 & $5.9 E-12$ \\
\hline f10s05-37 & $2.2 E-12$ \\
\hline f10s05-42 & $2.8 E-12$ \\
\hline f10s05-47 & $3.3 E-12$ \\
\hline f20s05-37 & $2.5 E-12$ \\
\hline $\mathrm{f} 20 \mathrm{~s} 05-42$ & $3.6 E-12$ \\
\hline $\mathrm{f} 20 \mathrm{~s} 05-47$ & $3.8 E-12$ \\
\hline g30s05-37 & $1.4 E-12$ \\
\hline g30s05-42 & $1.9 E-12$ \\
\hline g30s05-47 & $1.8 E-12$ \\
\hline g35f15-37 & $1.8 E-12$ \\
\hline g35f $15-42$ & $1.9 E-12$ \\
\hline g35f15-47 & $2.3 E-12$ \\
\hline
\end{tabular}

\section{Test Program for Apparent Diffusion Coefficient}

3.1. Outline of Test Program. In this section, tests for learning and training of NNA are explained. Thirty mix proportions for HPC are prepared. Target slump and air content are $150 \pm 15 \mathrm{~mm}$ and $4.5 \pm 1.0 \%$, respectively. Three w/b (water to binder) ratios are set as as $0.37,0.42$, and 0.47 . After 28 days of water curing, the specimens were kept in $3.5 \%$ of $\mathrm{NaCl}$ solution for 6 months. For 1-dimensinal intrusion of chloride ion, sides and bottoms were coated with epoxy except top surface. After 6 months of submerging in $\mathrm{NaCl}$ solution, chloride profiles were measured based on AASHTO $\mathrm{T}$ 260. Through regression of chloride profile, surface chloride contents and apparent diffusion coefficients are obtained. For binding materials, OPC (ordinary portland cement) was used. GGBFS (ground granulated blast furnace slag), FA (fly ash), and SF (silica fume) were added for mineral admixtures. In Table 1, chemical compositions and physical properties of cement and the used mineral admixtures are listed.

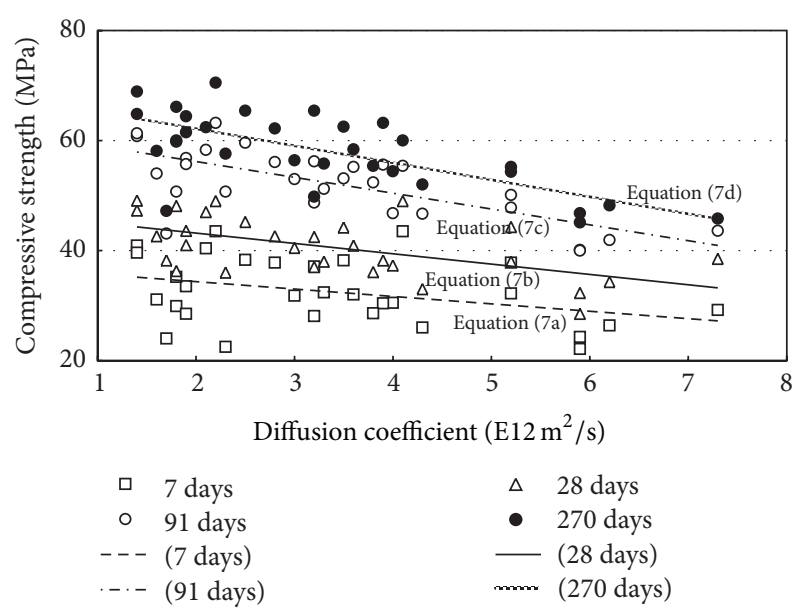

FIGURE 5: Relationship between compressive strength and diffusion coefficient.

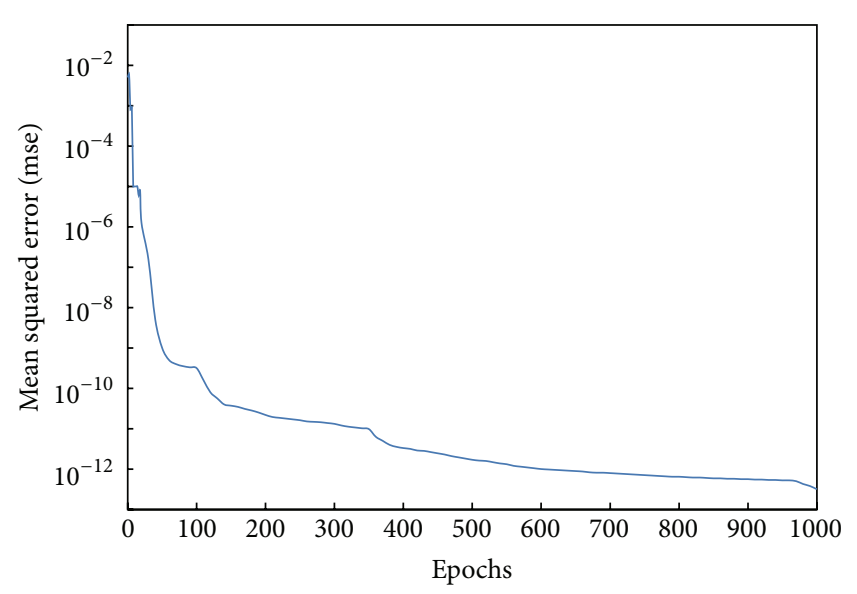

FIGURE 6: Decrease in errors with increasing epochs.

The physical properties of aggregates are listed in Table 2. Thirty mix properties which are used for learning and training of NNA are listed in Table 3.

\subsection{Test Results}

3.2.1. Compressive Strength with Ages. Compressive strength is measured at the age of 7, 28, 91, and 270 days. In Figure 3, the results of compressive strength with different ages are shown. The results show typical strength development, higher strength with lower $\mathrm{w} / \mathrm{b}$ ratio. The smallest strength at the age 7 days is measured in $\mathrm{f} 30070$ (30\% replacement of FA) in Figure 3. Compared with the results in OPC, the strength ratio is only 69.9\%, however, in the long term (270 days), concrete with mineral admixtures mostly shows higher strength than OPC concrete. It is reported that the ability of a mineral admixture to react with calcium hydroxide present in the hydrated Portland cement paste and to form additional calcium silicate hydrates can lead to significant reduction in 
TABLE 5: Result of multiregression analysis.

\begin{tabular}{lccccccc}
\hline \multicolumn{7}{c}{$D=\left[a_{1}(w / b)+a_{2}\left(C_{e}\right)+a_{3}(\mathrm{GGBFS})+a_{4}(\mathrm{FA})+a_{5}(\mathrm{SF})+a_{6}(S)+a_{7}(G)+I\right] \times 10^{-15}$} \\
$a_{1}$ & $a_{2}$ & $a_{3}$ & $a_{4}$ & $a_{5}$ & $a_{6}$ & $a_{7}$ & $I$ \\
\hline 293.86 & 26.58 & 11.01 & 24.34 & -42.41 & 12.78 & 11.80 & -39491.61 \\
\hline
\end{tabular}

TABLE 6: Mix proportions for verification (long-term submerged condition).

\begin{tabular}{|c|c|c|c|c|c|}
\hline \multirow{2}{*}{ Type } & \multirow{2}{*}{$\mathrm{w} / \mathrm{b}$} & \multicolumn{2}{|c|}{ Binder $\left(\mathrm{kg} / \mathrm{m}^{3}\right)$} & \multirow{2}{*}{ Sand $\left(\mathrm{kg} / \mathrm{m}^{3}\right)$} & \multirow{2}{*}{ Coarse aggregate $\left(\mathrm{kg} / \mathrm{m}^{3}\right)$} \\
\hline & & $\mathrm{C}$ & FA & & \\
\hline OPC $100 \%$ & 38.1 & 449 & 0 & 616 & 1,050 \\
\hline OPC $80 \%$ and $\mathrm{FA} 20 \%$ & 38.1 & 359 & 90 & 616 & 1,050 \\
\hline
\end{tabular}

porosity of both the matrix and the transition zone. Consequently, considerable improvement in ultimate strength and water-tightness can be achieved by incorporation of mineral admixtures [25]. Silica fume is very effective to strength development both in the short and in the long term. In the case of 270 days, the highest strength is measured in $\mathrm{f} 10 \mathrm{~s} 05$ (17.5\% increase for OPC result, w/b 0.37), g30s05 (16.7\% increase for OPC result, w/b 0.42), and g30s05 (31.0\% increase for OPC result, w/b 0.47). In many researches, the effect of silica fume is found to be considerable both to strength and to durability $[26,27]$.

3.2.2. Apparent Diffusion Coefficient. In Table 4, the results of apparent diffusion coefficient are listed. The maximum and minimum results are measured in o100-47 $(7.3 \times$ $\left.10^{-12} \mathrm{~m}^{2} / \mathrm{sec}\right)$ and g30s05-37 $\left(1.4 \times 10^{-12} \mathrm{~m}^{2} / \mathrm{sec}\right)$, respectively. The lower $\mathrm{w} / \mathrm{b}$ ratio concrete has, the lower diffusion coefficients are measured. The mix proportions with mineral admixture have lower results than those with only OPC. Since the mix proportions with lower w/b ratio and large amount of binder have more hydrates amount and smaller porosity, penetration of chloride ion is impeded $[7,13,15]$. Concrete with FA can have large amount of hydrates due to pozzolan reaction and this leads low diffusion of chloride ion. In the case of GGBFS, low diffusion coefficients are measured due to the small porosity from latent hydraulic properties and chemical binding of chloride ion $[5,6,28]$. The comparisons of mineral admixture group with OPC series are shown in Figure 4.

In order to evaluate the relationship between strength and diffusion coefficient, linear regression analysis is performed and the results are shown in Figure 5 with test results.

The regression results are listed in $(7 \mathrm{a}) \sim(7 \mathrm{~d})$.Consider

$$
\begin{aligned}
& C_{3}=-1.3477 D+37.064, \\
& C_{28}=-1.8815 D+46.954, \\
& C_{91}=-2.8811 D+61.963, \\
& C_{270}=-3.0938 D+68.342,
\end{aligned}
$$

where $C_{i}$ denotes the compressive strength $(\mathrm{MPa})$ at $i$ days, $D$ is measured diffusion coefficient $\left(\times 10^{12} \mathrm{~m}^{2} / \mathrm{sec}\right)$. It is observed the gradients of (7a), (7b), (7c), and (7d) increase with ages and this shows higher strength is related with lower diffusion coefficient with aging.

3.2.3. NNA Application to Diffusion Coefficient. NNA technique is applied to simulation of diffusion coefficient and the results are compared with those from multiregression analysis. Seven mix components like w/b ratio, unit content of cement, GGBFS, FA, SF, sand, and coarse aggregate are considered as input neurons. Output neuron is fixed as apparent diffusion coefficient. MATLAB program is used for this regression analysis. Back propagation algorithm is adopted and Tan-Sigmoid function is used for transfer function among various functions like linear transfer and logsigmoid [24]. Training number is set as 2,000 and the error to target convergence is set as $10^{-12}$ for learning process. The number of neuron is only 7 so that the simulation is usually completed within 2,000 trials. The decrease in error with increasing epoch is shown in Figure 6.

In Table 5, the result from multiregression analysis is listed. From the analysis, the average of relative error is $19.8 \%$, which is reasonable; however $70.6 \%$ of relative error is calculated in the case of g50050-47.

In Figure 7, the results from multiregression in Table 5 are compared with those from NNA and experiment. The results from NNA show more reasonable prediction with average relative error of $4.1 \%$, which is very close to test results compared with $19.8 \%$ of average relative error from multiregression analysis. The comparisons of relative error from each technique are shown in Figure 8.

The chloride profiles based on the diffusion coefficient from NNA are compared with test results which were kept in submerged condition for 6 months in Figure 9. Concrete with lower w/b ratio and larger mineral admixture shows the more reduced chloride penetration. The proposed technique shows reasonable prediction for chloride penetration.

\section{Analysis Technique of Chloride Penetration with Time-Dependent Diffusion}

4.1. Time-Dependent Diffusion of Chloride Ion. It is reported that chloride diffusion coefficient based on Fick's 2nd law decreases with time $[3,8]$. The governing equation for 
TABLE 7: Analysis conditions for verification (submerged condition).

\begin{tabular}{lcccc}
\hline Type & $m$ & $\begin{array}{c}D \text { from NNA } \\
\left(\mathrm{m}^{2} / \mathrm{sec}\right)\end{array}$ & $\begin{array}{c}D_{28} \\
\left(10^{-12} \mathrm{~m}^{2} / \mathrm{sec}\right)\end{array}$ & $\begin{array}{c}\text { Surface chloride content } \\
(\% \text { of concrete wt. })\end{array}$ \\
\hline OPC 100\% & 0.2 & 2.509 & 2.912 & 0.709 \\
OPC 80\% and FA 20\% & 0.36 & 1.801 & 2.252 & 0.709 \\
\hline
\end{tabular}

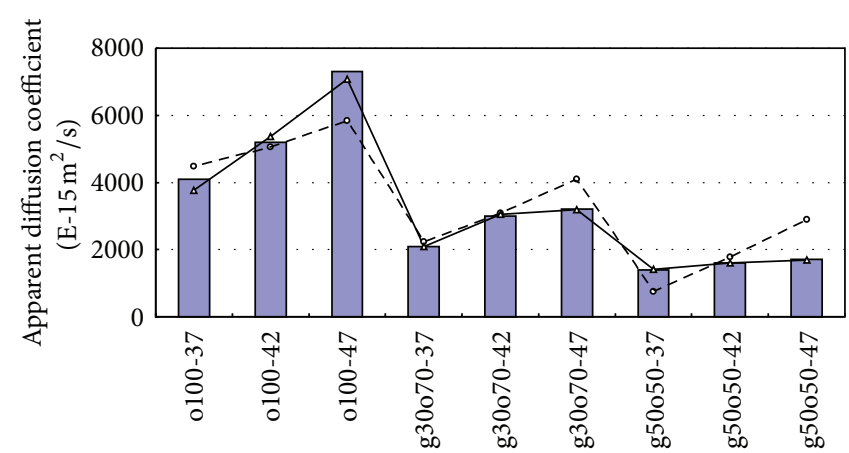

(a) OPC and GGBFS series

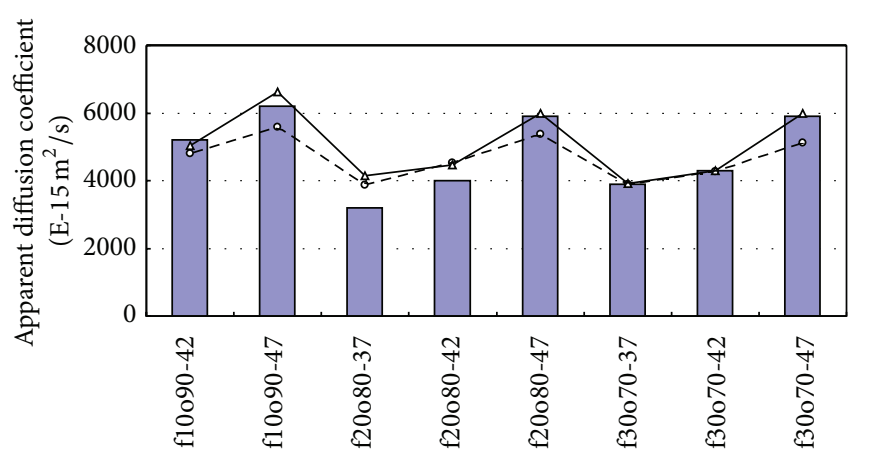

(b) FA series

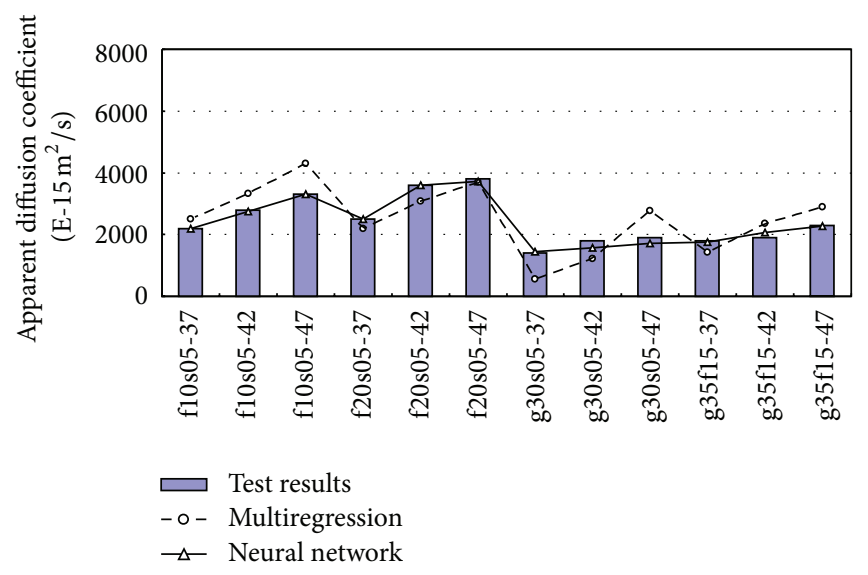

(c) Combined series

FIGURE 7: Comparison with results from test, multiregression, and NNA.

chloride penetration is listed in (8) and time-dependent diffusion coefficient is listed in $(9)[3,8,16]$. Consider

$$
\begin{gathered}
C(x, t)=C_{s}\left[1-\operatorname{erf}\left(\frac{x}{2 \sqrt{D(t) \cdot t}}\right)\right], \\
D(t)=D_{0}\left(\frac{t_{0}}{t}\right)^{m},
\end{gathered}
$$

where, $t_{0}$ and $D_{0}$ are reference time (28 days) and diffusion coefficient at reference time, $D(t)$ is time-dependent diffusion coefficient. $m$ is time exponent which is changed with type and amount of mineral admixtures $[3,16]$, which is defined as

$$
m=0.2+0.4\left(\frac{\mathrm{FA}}{50}+\frac{\mathrm{SG}}{70}\right)
$$

where FA and SG denote the replacement ratio of fly ash and slag. For solving (8) with (9), numerical analysis like finite differential method should be employed, however if time term is fixed, averaged diffusion coefficient can be derived as (11a) and (11b) [29]. Consider

$$
\begin{gathered}
D(t)=\frac{1}{t} \int_{0}^{t} D_{0}\left(\frac{t_{0}}{\tau}\right) d \tau=D_{0} \frac{t_{0}^{m}}{t}\left[\frac{\tau^{1-m}}{1-m}\right]_{0}^{t}=\frac{D_{0}}{1-m}\left(\frac{t_{0}}{t}\right)^{m}, \\
\left(t<t_{c}\right), \\
D(t)=D_{0}\left[1+\frac{t_{c}}{t}\left(\frac{m}{1-m}\right)\right]\left(\frac{t_{0}}{t_{c}}\right)^{m}, \quad\left(t \geq t_{c}\right),
\end{gathered}
$$

where $t_{c}$ is the time after which diffusion coefficient keeps almost constant and it is usually assumed as 30 years.

4.2. Chloride Penetration Analysis Using NNA and TimeDependent Diffusion Coefficient. The diffusion coefficients from NNA are the results based on the test data which is 


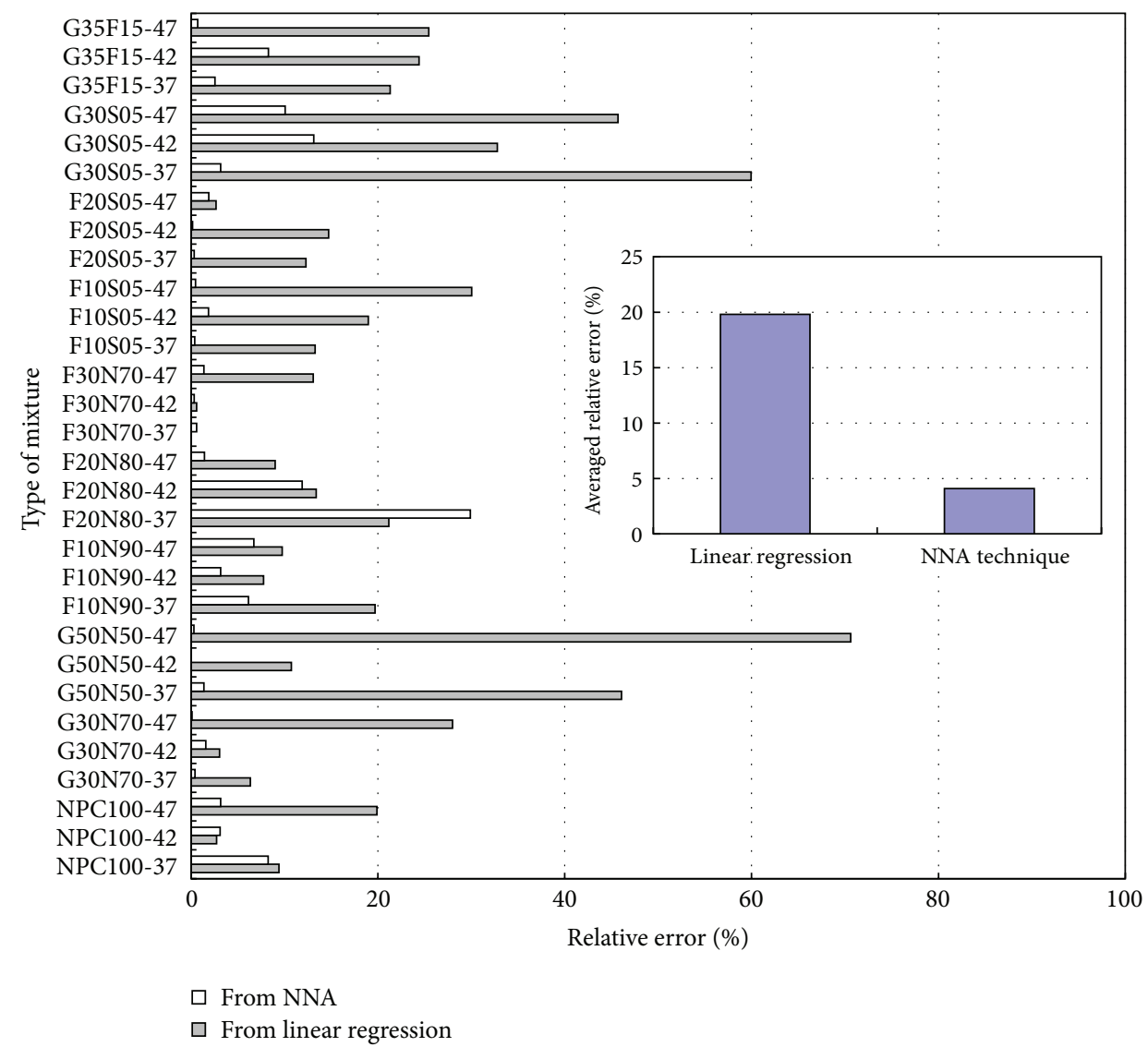

FIGURE 8: Comparison of relative errors from NNA and linear regression analysis with averaged relative errors.

obtained from 6 months submerged condition, so that they are converted to diffusion coefficient at the reference time $(28$ days). In Figure 10, analysis technique for chloride behavior using NNA is depicted.

4.3. Comparison with Previous Test Results. In this section, the results from the proposed technique are compared with the previous test results of chloride profiles. In the previous test [28], two types of concrete (FA and OPC) were kept in $3.5 \% \mathrm{NaCl}$ solution for 46 weeks. Table 6 shows the mix proportions [28].

Conditions for analysis are listed in Table 7 and the analysis results are shown in Figure 11. From Figure 11, it is found that the obtained diffusion coefficient seems to be small but the results from the analysis reasonably agree with the previous chloride profiles.

Another verification is performed using the results from field investigation. In the previous research [28], the chloride profiles were obtained from RC columns after 1 and 10 years in submerged condition. Unfortunately, mix proportions could not be obtained but it was found that it was made up with OPC concrete and w/c (water to cement ratio) was 0.55. Conventional mix proportions are assumed as Table 8 based on the domestic typical mix proportions [30] and analysis conditions are listed in Table 9.
TABLE 8: Mix proportions for verification (field investigation).

\begin{tabular}{lcccc}
\hline Type & w/c & $\begin{array}{c}\text { Cement } \\
\left(\mathrm{kg} / \mathrm{m}^{3}\right)\end{array}$ & $\begin{array}{c}\text { Sand } \\
\left(\mathrm{kg} / \mathrm{m}^{3}\right)\end{array}$ & $\begin{array}{c}\text { Coarse aggregate } \\
\left(\mathrm{kg} / \mathrm{m}^{3}\right)\end{array}$ \\
\hline OPC $100 \%$ & 55.0 & 352 & 653 & 1,173 \\
\hline
\end{tabular}

TABLE 9: Analysis condition for verification (field investigation).

\begin{tabular}{ccccc}
\hline Type & $m$ & $\begin{array}{c}D \text { from NNA } \\
\left(\mathrm{m}^{2} / \mathrm{sec}\right)\end{array}$ & $\begin{array}{c}D_{28} \\
\left(\mathrm{~m}^{2} / \mathrm{sec}\right)\end{array}$ & $\begin{array}{c}\text { Surface chloride content } \\
(\% \text { of concrete wt. })\end{array}$ \\
\hline $\begin{array}{l}\text { OPC } \\
100 \%\end{array}$ & 0.2 & 3.647 & 4.233 & 0.709 \\
\hline
\end{tabular}

In Figure 12, chloride profiles from field investigation are compared with the results from this study. With elapsed time, chloride profile moves to inside of concrete and the proposed technique is evaluated to reasonably predict the chloride penetration.

This study extends the applicability of NNA which is limitedly utilized for concrete strength and mix proportions to the research on durability. Through learning and training of diffusion coefficient, target value (diffusion coefficient) can be simulated in a given mix proportions. However this technique has still limitation since NNA technique closely 


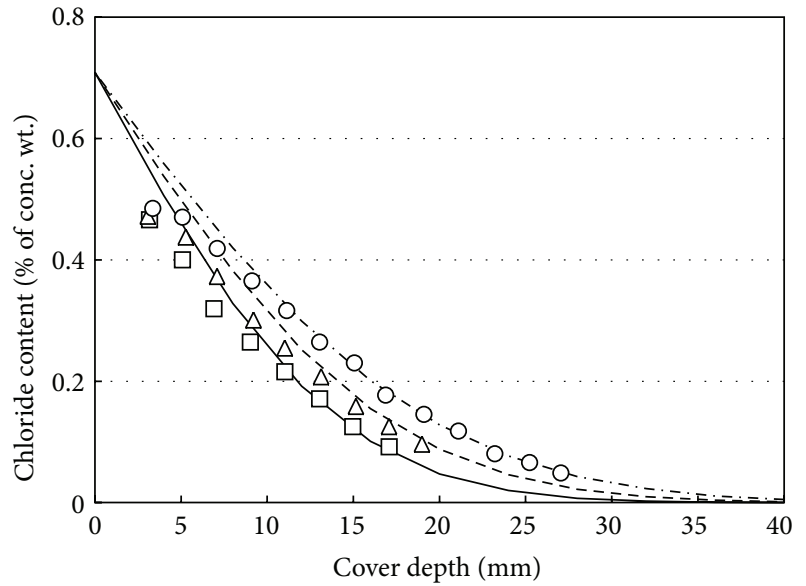

(a) Chloride profile in o100 series

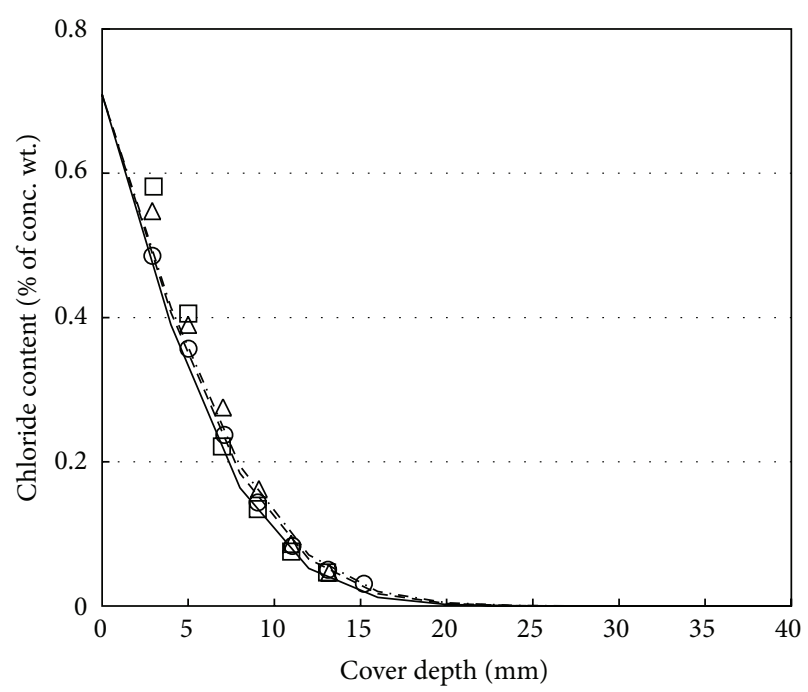

(c) Chloride profile in g50o50 series

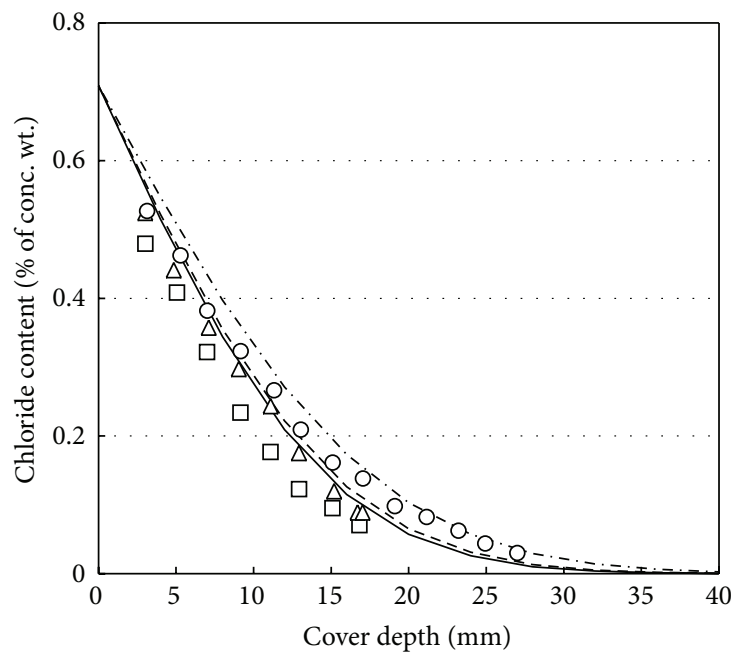

- Analysis w/b 37\%

- - Analysis w/b 42\%

...- Analysis w/b 47\%

(e) Chloride profile in $\mathrm{f} 20 \mathrm{o} 80$ series $\triangle$ Test w/b $42 \%$

○ Test w/b $47 \%$ $\square$ Test w/b 37\%

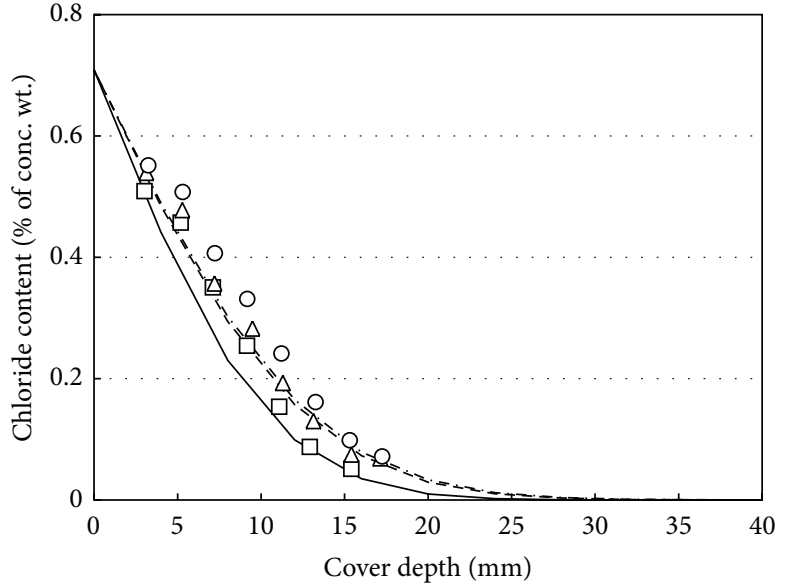

(b) Chloride profile in g30o70 series

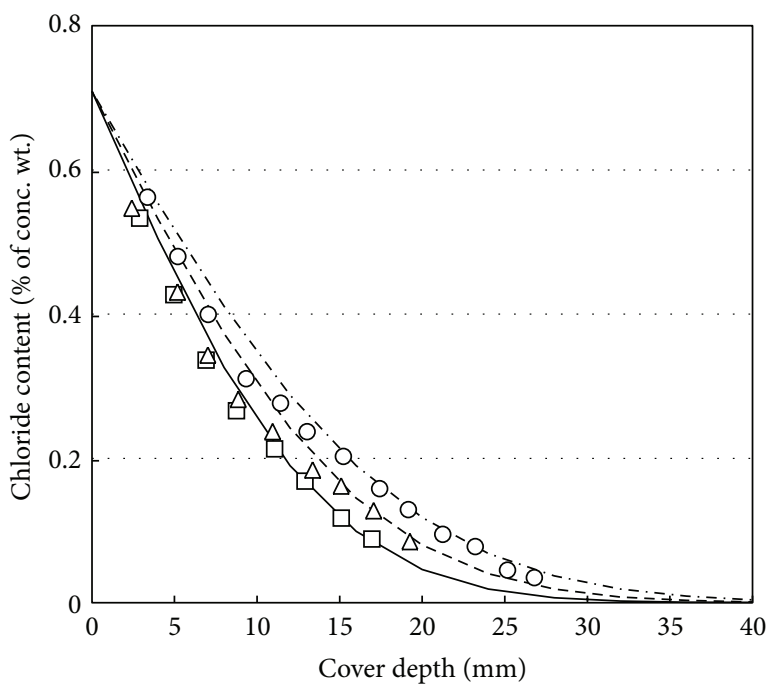

(d) Chloride profile in f10o90 series

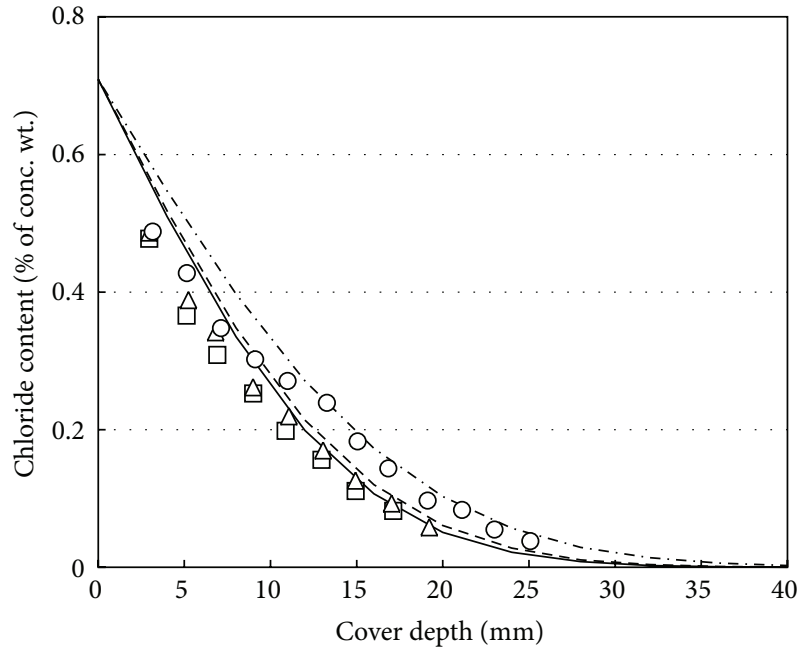

- Analysis w/b 37\%

-- - Analysis w/b 42\%

- - Analysis w/b 47\%

(f) Chloride profile in $\mathrm{f30o} 70$ series

FIgUre 9: Continued. 


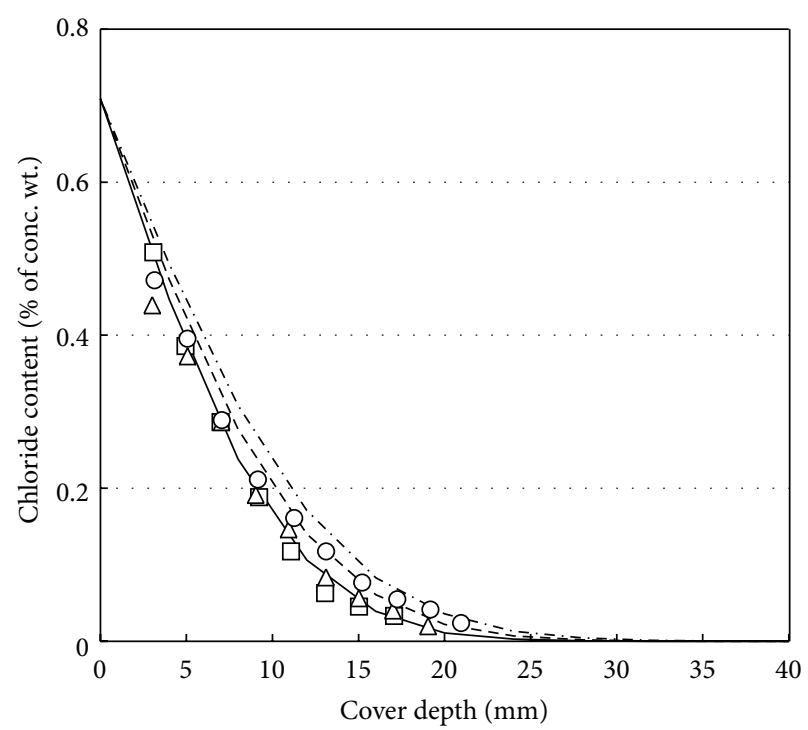

(g) Chloride profile in f10s05 series

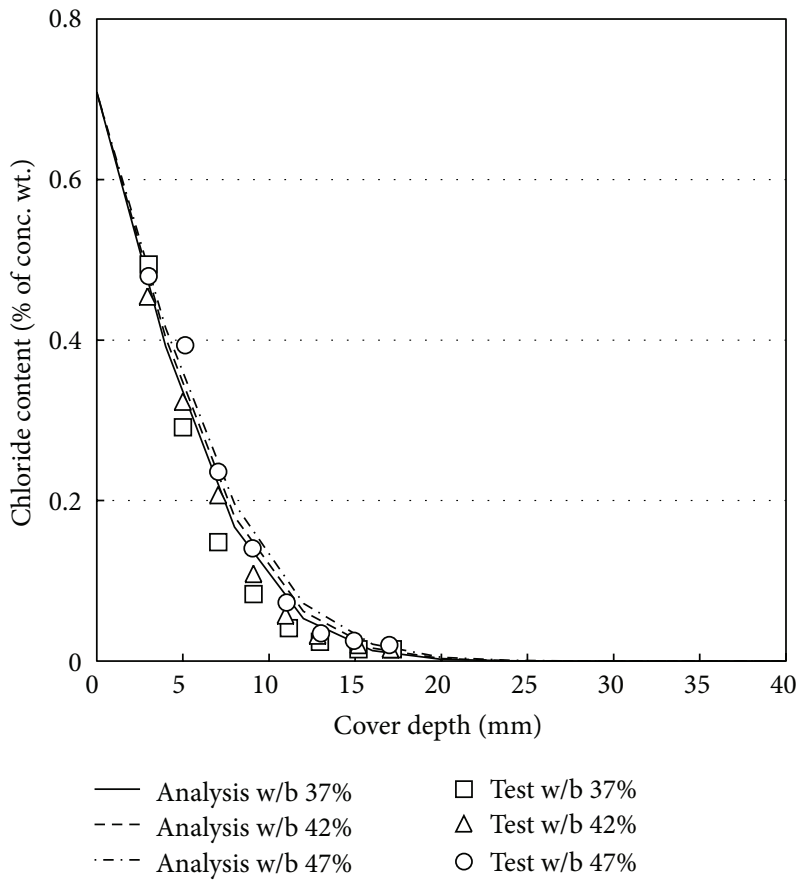

(i) Chloride profile in g30s05 series

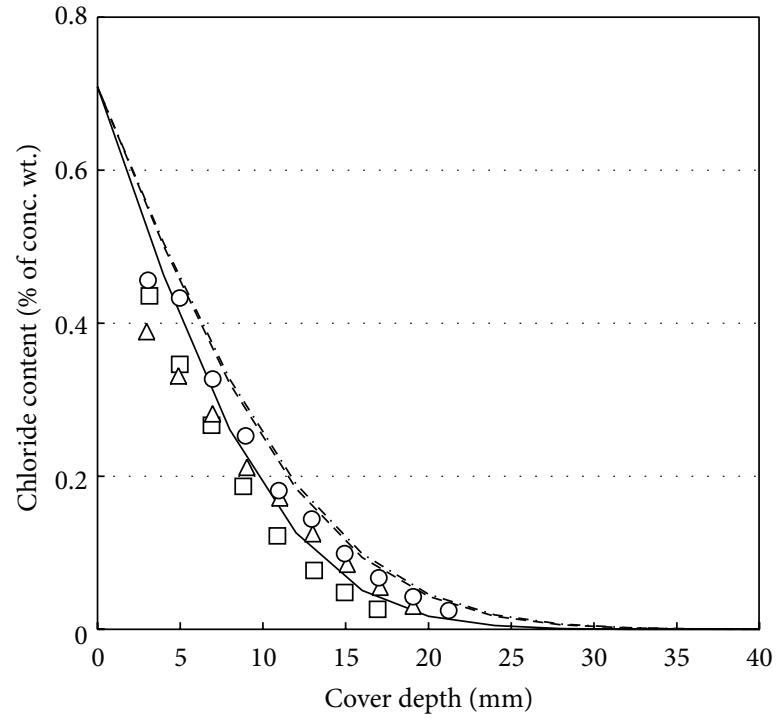

(h) Chloride profile in $\mathrm{f} 20 \mathrm{~s} 05$ series

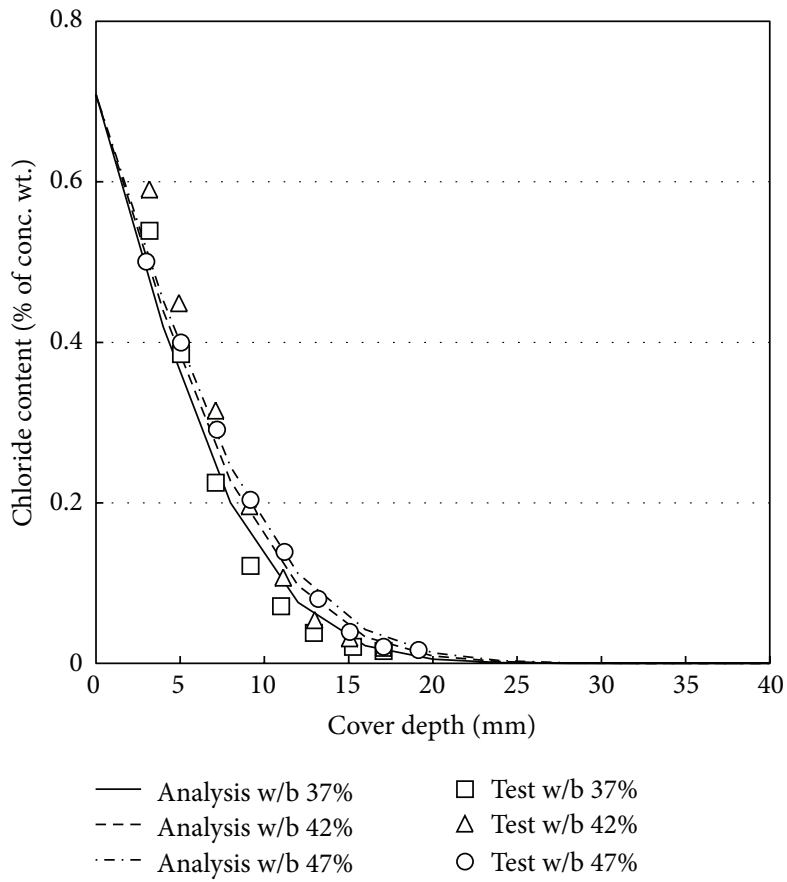

(j) Chloride profile in g35f15 series

FIGURE 9: Comparison of chloride profile between NNA and test results.

depends on data set for training. The data in this paper has limitary material properties like w/b (0.37 0.47) and diffusion coefficient $\left(1.4 \sim 7.3 \times 10^{-12} \mathrm{~m} / \mathrm{sec}^{2}\right)$ so that it is necessary to extend the range for enhancing application. Various mix proportions with mineral admixtures and variability of surface chloride content will be considered for future study.

\section{Conclusions}

The conclusions evaluation technique of chloride penetration using apparent diffusion coefficient and neural network algorithm are as follows.
(1) Thirty mix proportions for HPC containing GGBFS, $\mathrm{FA}$, and SF are prepared and apparent diffusion coefficients are obtained after 6-month submerged condition of $\mathrm{NaCl} 3.5 \%$. Seven mix components (w/b, unit content of cement, GGBFS, FA, SF, and fine/coarse aggregate) are selected as neurons and NNA is applied to simulation of diffusion coefficient. The simulated data shows only $4.1 \%$ of relative error, which is very accurate compared with the results from multiregression analysis showing $19.8 \%$.

(2) Utilizing diffusion coefficient from NNA and timedependent diffusion, chloride profiles are evaluated. 


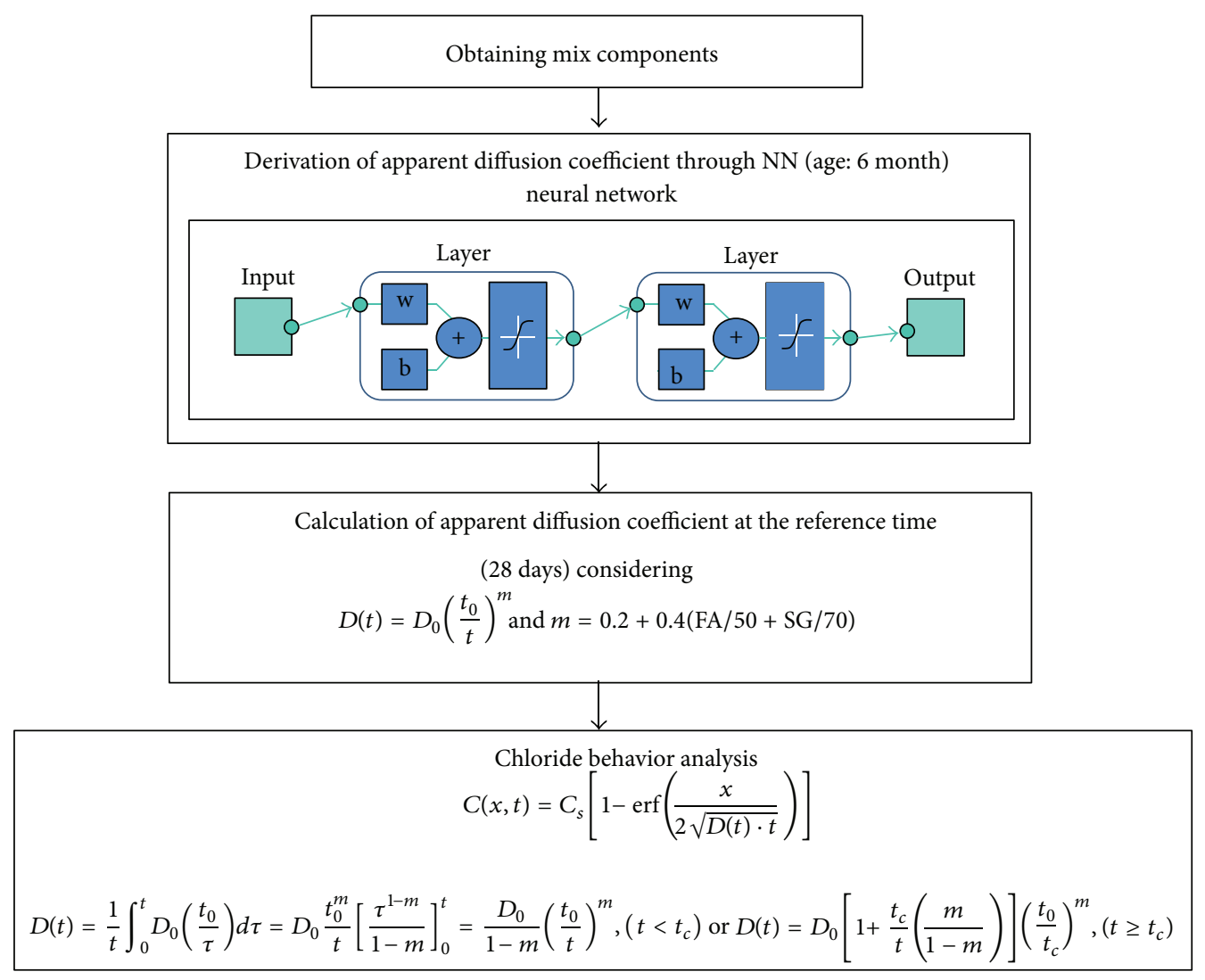

FIgURE 10: Prediction of chloride penetration using NNA and time-dependent diffusion.

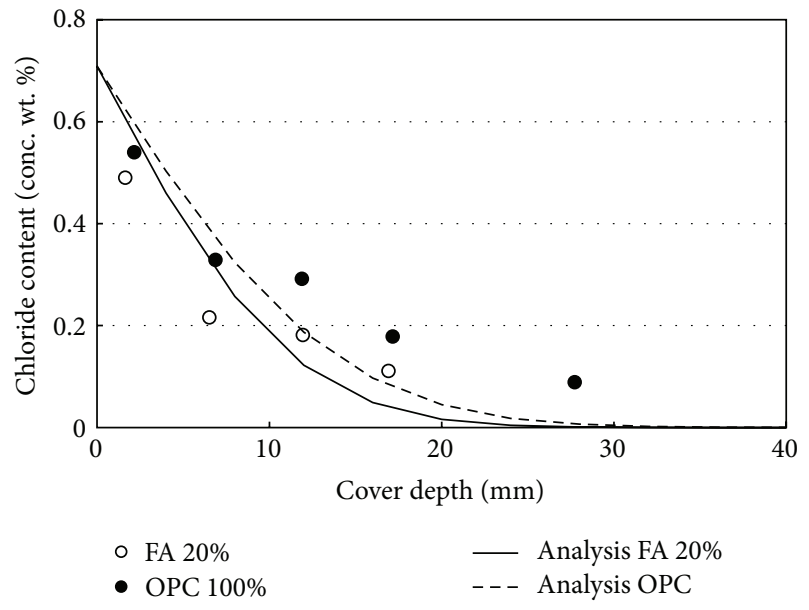

FIGURE 11: Chloride profile between results from test and this study.

From the comparison with results of long term submerging test and field investigation, the proposed technique is evaluated to reasonably predict the induced chloride profile.

(3) The proposed technique is closely dependent on quantitative data set for training and learning. With

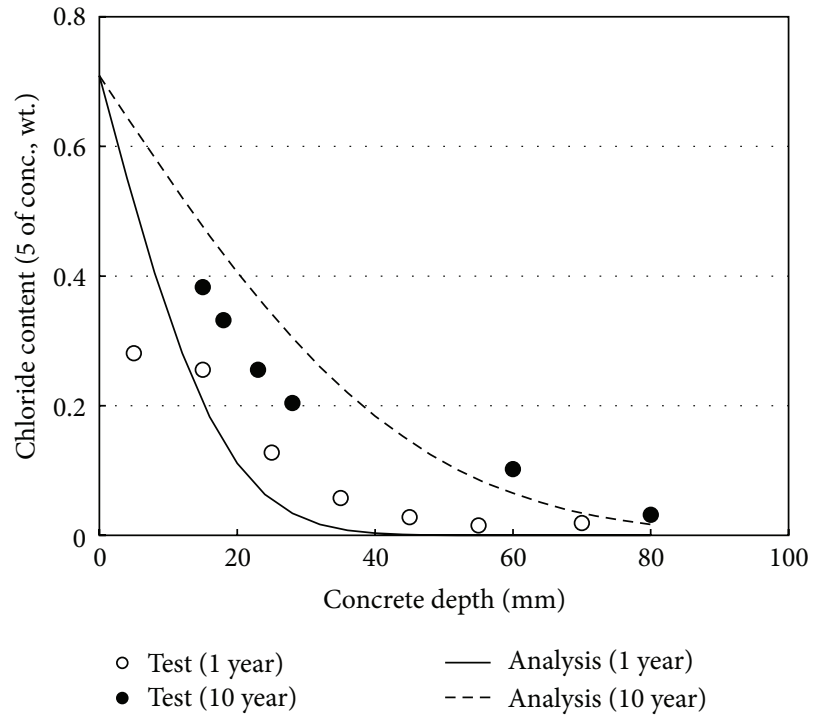

FIGURE 12: Chloride profile between results from field investigation and this study.

more extended mix proportions and the related diffusion coefficients, this technique can be modified and more applicable to evaluation of chloride penetration. 


\section{Conflict of Interests}

The authors declare that there is no conflict of interests regarding the publication of this paper.

\section{Acknowledgment}

This research was supported by Grant (Code 11-Technology Innovation-F04) from Construction Technology Research Program (CTIP) funded by Ministry of Land, Infrastructure, and Transport.

\section{References}

[1] J. P. Broomfield, Corrosion of Steel in Concrete: Understanding, Investigation and Repair, EE \& FN Spon, London, UK, 1997.

[2] RILEM, "Durability design of concrete structures," Report of RILEM technical committee 130-CSL, E\&FN, 1994.

[3] M. D. A. Thomas and E. C. Bentz, Computer Program for Predicting the Service Life and Life-Cycle Costs of Reinforced Concrete Exposed to Chlorides, Life 365 Manual, SFA, 2002.

[4] CEB-FIP, "Model code for service life design," International Federation for Structural Concrete (fib), Task Group 5.6, 2006.

[5] H.-W. Song, S.-W. Pack, C. H. Lee, and S. -J. Kwon, "Service life prediction of concrete structures under marine environment considering coupled deterioration," Restoration of Buildings and Monuments, vol. 12, pp. 265-284, 2006.

[6] K. Maekawa, T. Ishida, and T. Kishi, "Multi-scale modeling of concrete performance," Journal of Advanced Concrete Technology, vol. 1, no. 2, pp. 91-126, 2003.

[7] H.-W. Song, S.-J. Kwon, K.-J. Byun, and C.-K. Park, "A study on analytical technique of chloride diffusion considering characteristics of mixture design for high performance concrete using mineral admixture," Journal of Korean Society of Civil Engineers, vol. 25, no. 1A, pp. 213-223, 2005.

[8] S. J. Kwon, U. J. Na, S. S. Park, and S. H. Jung, "Service life prediction of concrete wharves with early-aged crack: probabilistic approach for chloride diffusion," Structural Safety, vol. 31, no. 1, pp. 75-83, 2009.

[9] S.-S. Park, S.-J. Kwon, and S.-H. Jung, "Analysis technique for chloride penetration in cracked concrete using equivalent diffusion and permeation," Construction and Building Materials, vol. 29, pp. 183-192, 2012.

[10] NORDTEST, "Chloride migration coefficient from non-steadystate migration experiments," NT BUILD 492, 1999.

[11] L. Tang, Chloride Transport in Concrete, Publication P-96:6, Division of Building Materials, Chalmers University of Technology, Sweden, 1996.

[12] S. Park, S. Kwon, S. H. Jung, and S. Lee, "Modeling of water permeability in early aged concrete with cracks based on micro pore structure," Construction and Building Materials, vol. 27, no. 1, pp. 597-604, 2012.

[13] K. Maekawa, T. Ishida, and T. Kishi, Multi-Scale Modeling of Structural Concrete, Tylor\&Francis, London, UK, 1st edition, 2009.

[14] L. Tang, "Electrically accelerated methods for determining chloride diffusivity in concrete-current development," Magazine of Concrete Research, vol. 48, no. 176, pp. 173-179, 1996.

[15] C. Arya, N. R. Buenfeld, and J. B. Newman, "Factors influencing chloride-binding in concrete," Cement and Concrete Research, vol. 20, no. 2, pp. 291-300, 1990.
[16] M. D. A. Thomas and P. B. Bamforth, "Modelling chloride diffusion in concrete effect of fly ash and slag," Cement and Concrete Research, vol. 29, no. 4, pp. 487-495, 1999.

[17] J. Wang, H. Ni, and J. He, "The application of automatic acquisition of knowledge to mix design of concrete," Cement and Concrete Research, vol. 29, no. 12, pp. 1875-1880, 1999.

[18] I.-C. Yeh, "Modeling of strength of high-performance concrete using artificial neural networks," Cement and Concrete Research, vol. 28, no. 12, pp. 1797-1808, 1998.

[19] J. A. Stegemann and N. R. Buenfeld, "Prediction of unconfined compressive strength of cement paste with pure metal compound additions," Cement and Concrete Research, vol. 32, no. 6, pp. 903-913, 2002.

[20] K.-B. Park, T. Noguchi, and J. Plawsky, "Modeling of hydration reactions using neural networks to predict the average properties of cement paste," Cement and Concrete Research, vol. 35, no. 9, pp. 1676-1684, 2005.

[21] H.-W. Song and S.-J. Kwon, "Evaluation of chloride penetration in high performance concrete using neural network algorithm and micro pore structure," Cement and Concrete Research, vol. 39, no. 9, pp. 814-824, 2009.

[22] S. Kwon and H. Song, "Analysis of carbonation behavior in concrete using neural network algorithm and carbonation modeling," Cement and Concrete Research, vol. 40, no. 1, pp.119$127,2010$.

[23] W. McCulloch and W. Pitt, "A logical calculus of the ideas immanent," The Bulletin of Mathematical Biophysics, vol. 5, no. 4, pp. 115-133, 1943.

[24] H. Demuth and M. Beale, Neural Network Toolbox: User's Guide, The MathWorks, 1997.

[25] A. M. Neville, Properties of Concrete, Longman, 4th and final edition, 1996.

[26] H.-W. Song, J.-C. Jang, V. Saraswathy, and K.-J. Byun, "An estimation of the diffusivity of silica fume concrete," Building and Environment, vol. 42, no. 3, pp. 1358-1367, 2007.

[27] S. A. Khedr and M. N. Abou-Zeid, "Characteristics of silicafume concrete," Journal of Materials in Civil Engineering, vol. 6, no. 3, pp. 357-375, 1994.

[28] S. Y. Jang, Modeling of chloride transport and carbonation in concrete and prediction of service life of concrete structures considering corrosion of steel reinforcement [Ph.D. thesis], Department of Civil Engineering, Seoul National University, Seoul, Republic of Korea, 2003.

[29] E. Poulsen, "On a model of chloride ingress into concrete," in Proceedings of the Nordic Mini-Seminar on Chloride Transport, pp. 1-8, Department of Building Materials, Chalmers University of Technology, Gothenburg, Sweden, 1993.

[30] KREA-Korean Remicon Engineering Association, "Concrete Mix Proportions," 2005, (Korean). 

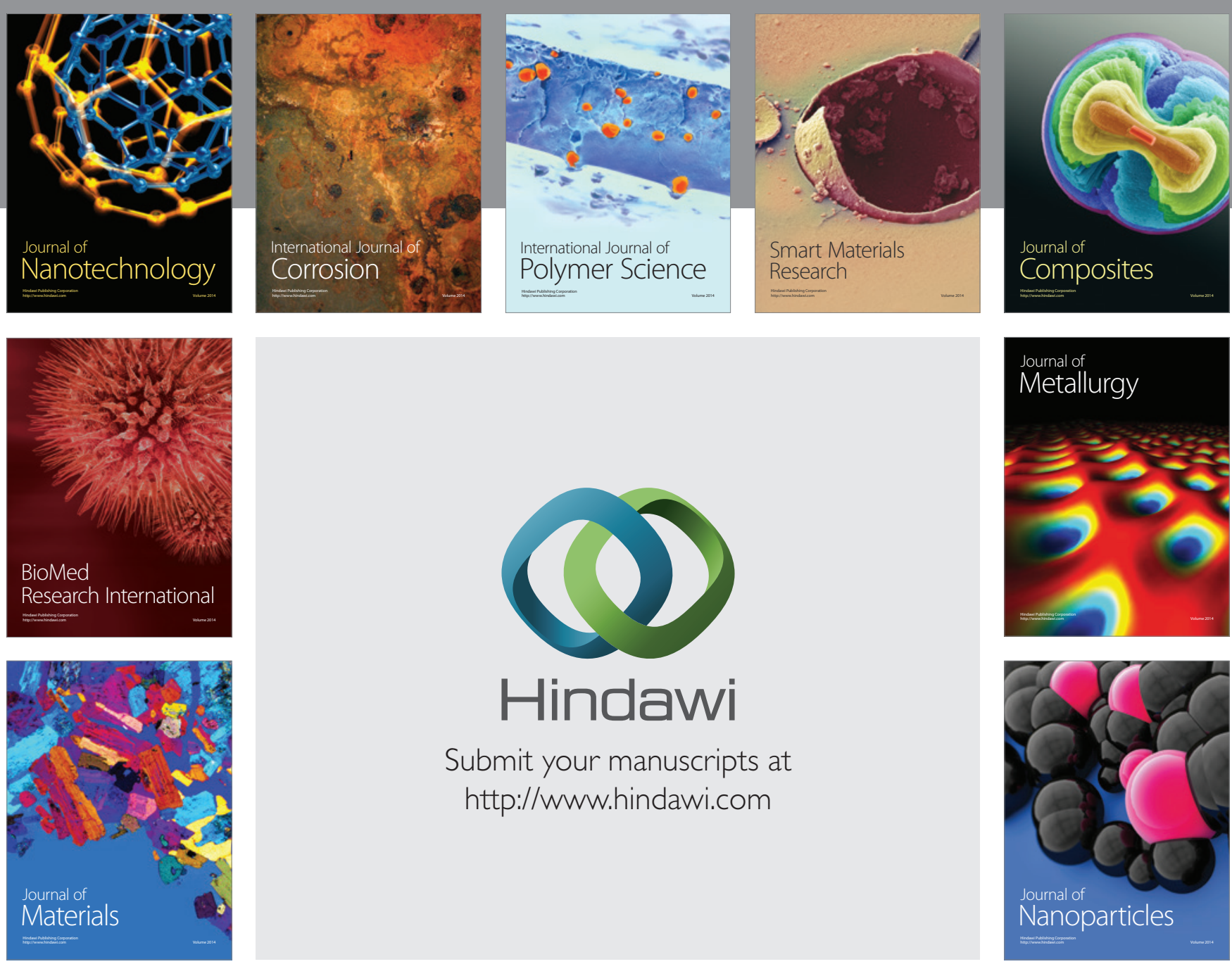

Submit your manuscripts at http://www.hindawi.com
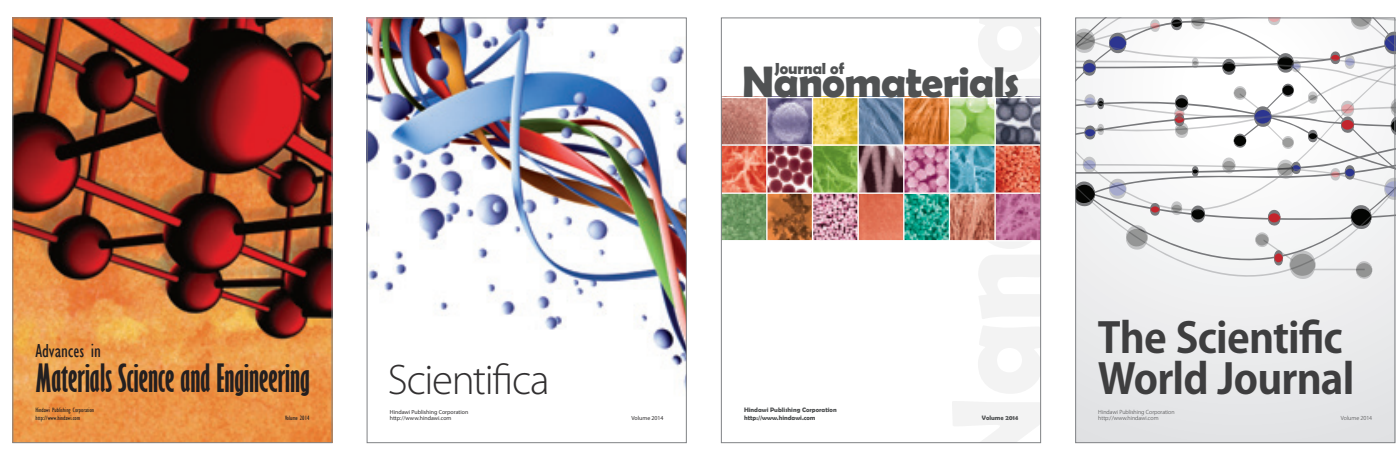

\section{The Scientific World Journal}
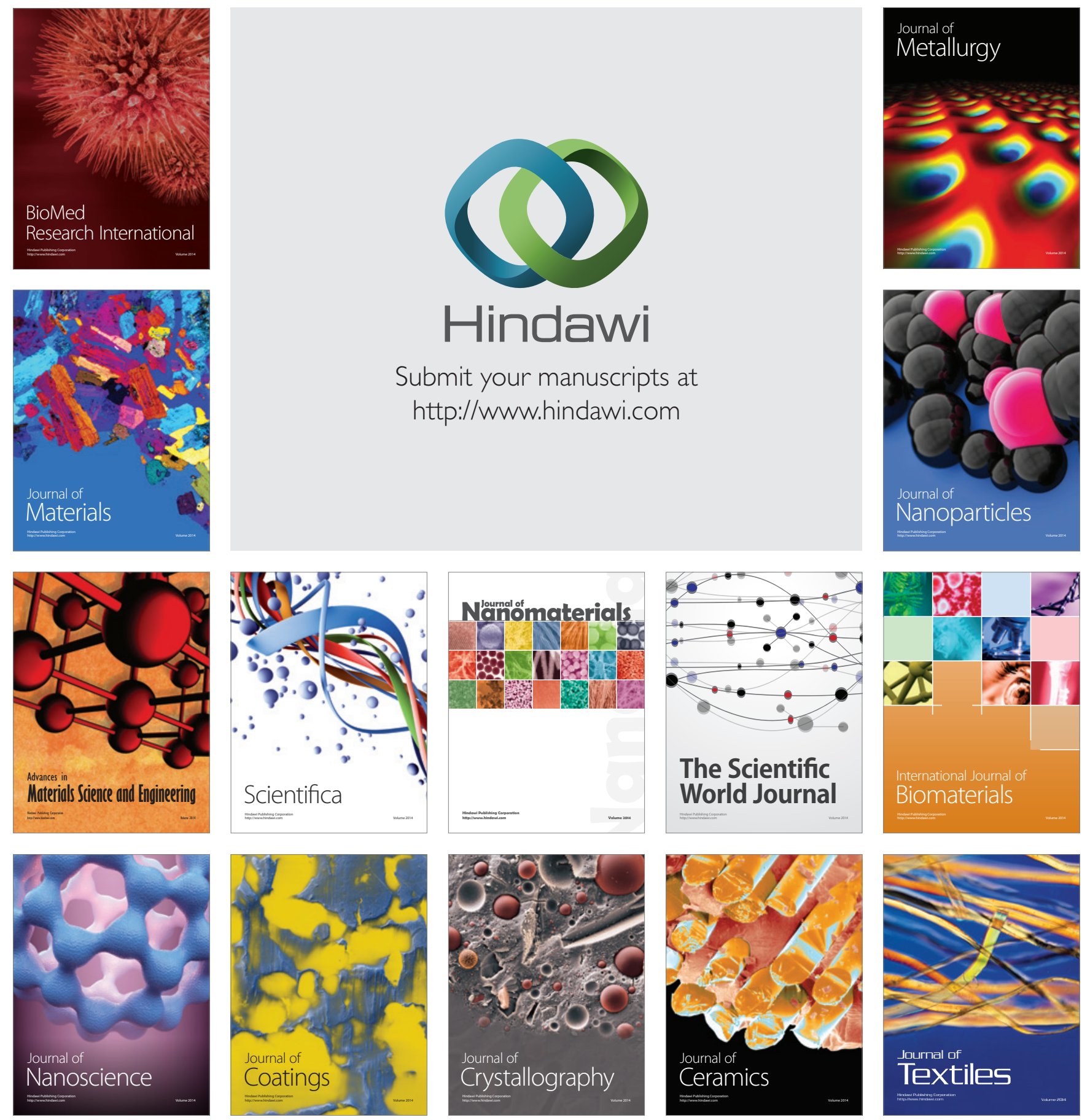